\title{
Eesti keele maailmapildist: meel, hing ja vaim
}

Maailmapildi all ei mõista ma mingit filosoofilist terminit. Maailmapilt on siin argimõiste, mis väljendab meie või meie esivanemate arusaama maailmast, asjade ja nähtuste vahelistest seostest jne. Maailmapilt juhib kõige üldisemalt inimeste elu ja käitumist.

Maailmapildis on lihtsamaid ja keerukamaid osi, selle võib jagada inimese tegevusvaldkondade järgi osadeks. Maailmapilti kuuluvad suhted teiste inimeste ja loodusega, siin- ja teispoolsus, maailma ruumilisus ja terviklikkus. Maailmapildi saab jagada ka asiseks ja mentaalseks. Viimane ongi kõige huvitavam, aga ka kõige raskemini tabatav. Mentaalsesse maailmapilti kuuluvad niisugused mõisted nagu ise, hing, vaim, meel, jume ehk jumi, jumal jt.

Rahva maailmapildi aluseks on rahvatarkus, mis struktureerib maailma ja sellele vastavat maailmapilti. Rahvatarkus kasutan eestikeelse vastena ingliskeelsetele terminitele folk model, folk theory või ka naive model, naive theory. Rahvatarkuse põlvest põlve edasiandmisel on kõige olulisem keel. Muutuvad aga mõlemad, nii maailmapilt kui ka keel. Järgnevalt püüan näidata, et keel mäletab vana rahvatarkust ja sellele vastavat maailmapilti, ilma et keele kandjad, s.t meie, seda ise märkaksimegi.

Selles kirjutises analüüsin meie esivanemate mentaalse maailmapildi olulisi mõisteid, nagu ise, hing, vaim ja meel. Taustaks vaatlen ka kreeka, semiidi ja germaani hingemõisteid ja nende muutumist. Lisaks osutan vajadusele eristada edaspidi keelematerjali analüüsil võõrmõjud ning tuua seejärel välja meie esivanemate mentaalse maailmapildi kihistused. Muidu võime sünkroonse keelematerjali analüüsi põhjal teha valesid järeldusi.

Eesti keele mentaalset maailmapilti on püüdnud analüüsida Haldur Õim (1997), kelle järgi seisab see kolmel vaalal - hing, vaim ja meel. Lauri Vahtre (1985) on väitnud, et soonimena kasutatakse ikkagi sõna hing. L. Vahtre arvates ei luba keelevaist sõna vaim hingega samastada, nad ei ole sünonüümid, aga nende täpsem vahekord on selgusetu. Ta esitab isegi küsimuse: Mida me selle sõna- 


\section{Urmas Sutrop}

ga [vaim] üldse tähistame; mis on vaim? Ning lisab, et siin peavad appi tulema keeleteadus ja keeleajalugu.

Hing ja vaim moodustavad Haldur Õimu järgi uuema kihistuse, meel aga kuulub mentaalse maailmapildi vanemasse kihti. H. Õim tuleb keelematerjali analüüsi põhjal järeldusele, et eestlase hing pesitseb südame piirkonnas, sest väljend kogu hingest tähendab sama mis kogu südamest; hing on raske väljendab sama mis süda on raske ning hingevalu on samane südamevaluga. Sellega tuleb nõustuda, sest hing oli nn hingushing ja tähendas muiste hingamist. Hingame aga rinnaga ja ütleme vahel praegugi, et hing on rinnus kinni. Süües-juues võtame midagi hinge alla, vaesel mehel pole midagi hinge taga. Hing oli igatahes midagi asist. Kui me ei taha millegi eest vastutada, siis ütleme, et ei taha seda (pattu) oma hinge peale võtta. Hing aga samastub lõpuks inimesega, sest vahel ütleme, et kusagil (nt toas) pole hingegi, s.t seal pole kedagi.

Kus vaim pesitseb, sellele polegi nii lihtne vastata. Uku Masingu (1909-1985) arvates tähendas sõna vaim algul tuksumist, mis elustab keha (Masing 1995: 92). Autori eluajal ja pikka aega vaid käsikirjades levinud Salomo Heinrich Vestringi (1663-1749) sõnaraamatus (Vestring 1998: 278) esitatud Waimoke märgib pulssi (der Puls), mis on ju samuti veresoonte tuksumine, tuikamine (vrd ka tuiksoon). Sellest tähendusest on konkretiseerunud ka näiteks saami vaibmo, vaimo, mis nüüd tähendab südant (süda aga tuksub). Uku Masing oletab, et vaim on mingis ühenduses seksuaalvallaga. Näiteks kinnitab tüdruk oma vanematele, kes teda noomivad poisiga magamise pärast: Ta [poiss] ep ole ühtegi oma vaimu mu peale puhunud (Masing 1995: 81). U. Masingu arvates oletati üht mehe hinge asuvat naises. Kas ka vastupidi, seda tema kirjutistest ei selgu. Kuna aga mees ja naine moodustasid terviku, siis vaimu asumine mehe teises pooles oleks päris usutav. Muistne hinge paralleelnimetus vaim on soome keeles hakanudki tähistama (abielu)naist (vrd soome vaimo) (vt Sutrop 1999).

Seda, et vaim võib olla seotud seksuaalvallaga, kinnitab ka Oskar Loorits (1900-1961): Ka kuupuhastus ja järelsünnitus ehk päramised sisaldavad endas hinge, millega seletubki nende hoolas ja ettevaatlik käsitlemine [---] sugutamise all on mõeldud algselt elundeis sisalduva hingejõu edasiandmist (Loorits 1990: 10; esmatrükk ilmus 1932. aastal). Kahjuks ei ole teada, kuidas niisugust hinge (niisuguseid hingi) või hingejõudu nimetati. Arvata võib, et siin oli siiski tegemist vaimuga, kuna ka sugutamisega on seotud tuikamine 
ja tukslemine. Seda oletust toetavad gnostikud, kes samuti arvasid vaimu/hinge asuvat seksuaalvallas. 4 . sajandil $\mathrm{pKr}$ tegutsenud kirikuisa Epiphaniuse teatel leidus gnostikute hulgas äärmuslikke rühmitusi, kes menstruaalverd ja spermat rituaalselt kogusid ning sõid ja jõid, et neis leiduvat jumalikku vaimu või hinge (psyche) koguda ja oma hingega ühendada (vt Hasenfratz 1986: 70-76). (Hinge ja vaimu kohta vt ka Tarmo Kulmar (1997; 1998), Oskar Loorits (1990: 27-29, 49-55, 1998: 13-18), Ivar Paulson (1997: 126-146) ja Lauri Vahtre (1985)).

Meel asub peas, kus on ka meelekohad. Haldur Õim on märkinud, et meelekoht on sama koht, kuhu näitame sõrmega, kui tahame osutada, et kellegi mõtlemises midagi logiseb (Õim 1997: 267). Meel kajastab õieti juba vanemat, ununema kippuvat maailmapilti. H. Õimu arvates puudub tänapäeva eesti keeles mõiste, mis vastaks inglise sõnale mind. Muistne meel oma hajunud tähenduste ja ajaloolise taustaga vastaks sellele aga väga hästi. Kas meele kadumine vihjab tervikmaailmapildi lagunemisele, ähmastumisele, seda ei julge ma siin väita.

Samas ei ole hinge, vaimu ja meele vahekord üldsegi veel selge. Saksa keele mõjul on nende tähendused ja nendega seotud keelendid oluliselt muutunud. Uku Masingu järgi kuulutati ärkamisajal hing naiselikuks ja vaim mehelikuks. Vaim võrrutati täies ulatuses saksa sõnaga Geist (Masing 1995: 80). Hing on seetõttu enamasti saksa Seele, vahel harva ka Geist. U. Masingu arvates tehti saksa sõna Sinn vasteks meel, mis paljudel juhtudel sobiski. Saksa eeskujul avardati meie meele mahtu veelgi, kujundati viis meelt, lisaks veel huumori-ja ilumeel, meeleinstinktid, meeleorganid jt (Masing 1998: 360). Meie muistne nägemisvõimus või -võime sai saksa sunnil nägemismeeleks (Masing 1998: 358).

Kui tuletame meelde, et hing hakkas tähistama neid, kel hing sees - seega siis nii meest, naist kui ka looma, näiteks pole siin hingegi ehk hingelistki - , vaim aga hakkas tähistama naishingi (vrd vaimud 'naissoost abitöölised mõisas' ja soome vaimo '(abielu)naine'), siis näeme, kui koomiline oli kuulutada saksa eeskujul hing naiselikuks ning vaim mehelikuks. Ilmselt peitub selles koomilises vastuolus ka põhjus, miks soome keeles ei saanud naissugu märkivat sõna vaimo panna tähistama "mehelikku" Geisti mõistet. Nii saksa Seele kui ka Geisti soome vasteteks võivad olla henki, mieli jt (vrd saksa der heilige Geist (inglise Holy Ghost) eesti ja soome vasteid püha vaim ja Pyhä Henki). 


\section{Urmas Sutrop}

Kui tuleme meelemärkusele, siis tähendab see, et tuleme teadvusele ja meie meeled hakkavad jälle toimima. Ei saa kuidagi nõus olla Haldur Õimu väitega, et meelemärkus tähendas juba algul seisundit, kus meeled toimivad (Õim 1997: 266). Nagu eespool juba nimetasin, on viis meelt hilised saksa keele eeskujul loodud mõisted.

Võib-olla aitab meelte tähendust selgitada Jakob Hurda kogust pärinev Paulus Paurmanni ülestähendus (1889) Jõhvist väljendi muis meelis kohta:

Kui mõni inimene miski asja perast rahuta on, ja sääl juures mõnda nõdrameelelist juttu räägib ehk tego teeb, siis ööllässe: "See inimene on muis meelis" (vt Peebo ja Peegel 1989: 31, nr 2).

Järgnevalt vaatlen lühidalt hingemõisteid kreeklastel ja germaanlastel ühe uuema süstemaatilise hingekäsitluse (Seele) alusel. HansPeter Hasenfratz (1986) alustab oma analüüsi hantide ja manside hingemõistetest ning jõuab iraanlaste kaudu peagi kreeklaste juurde. Tänu hulgale vanadele tekstidele saame kreeklaste puhul jälgida huvitavat hingemõistete arengut ja muutumist.

Kreeklaste vanemat teadaolevat hingemõistete ajajärku nimetatakse Homerose psühholoogiaks. Surma järel lahkub psyche inimese kehast allilma Hadesesse. Psyche on elava inimese kujuline, aga kehatu nagu suits või hingetõmme (hingus). Allilmas on hinged (psychai) veretute varjudena, kellel ei ole mälestusi möödunust ega arusaamist hetkest. Selleks, et Odysseus nendega suhelda saaks, laseb ta neil verd juua (Odysseus 11, 152 jj, 225 jj). Seega elustab veri kehatud hinged ja annab neile mälu.

Ka elusal inimesel võib psyche kehast lahkuda, seda siis, kui inimene on teadvuseta olekus, või vahel ka une ajal. Seega pole psychel mingit pistmist normaalse eluga, kui inimene on ärkvel, s.t teadvuse juures. Psyche oli irdhing (Exkursionsseele). Ärkvelolijaid juhtis Homerose kaasaegsete arvates nende hing thymos, mis oli ühteaegu keha elustaja, ja teadvus, seega elus- ja minahing (Vitalja Ichseele). Thymos asus inimese rinnas, täpsemini vahelihases (phren). Teadvust tähistatigi selle sõna mitmusliku vormiga phrenes. Allilmas oli psyche ilma teadvuseta (phrenes), sest ta lahkus varjuna nii surnud kehast kui ka elujõu kaotanud hingeorganitest. Elushinge thymose juurde kuulusid veel eristunud väed, nagu nóos (mõtlemine), ménos (tahe, iha, ka elujõud) ning kardía (süda, kus võisid asuda mõtlemine, tahe, iha ja elu). 
Hiljem, Platonil langevad irdhing psyche ning elus- ja minahing thymos koos oma vägedega kokku ühtseks surematuks hingeks psyche, kus asub peale elus-, mina- ja irdhinge ka ümberkehastushing (Reinkarnationsseele). Pärast Platonit (tegelikult juba Platoni hilistes tekstides) hakkab ühtne hingemõiste psyche lagunema. Homerose surematu psyche kohale asuvad nūs, logos ja pneuma ning sureliku thymose (nóos, ménos, kardía) asemele psyche. Seega on psyche ja nóos / nūs osad nüüd vahetunud:

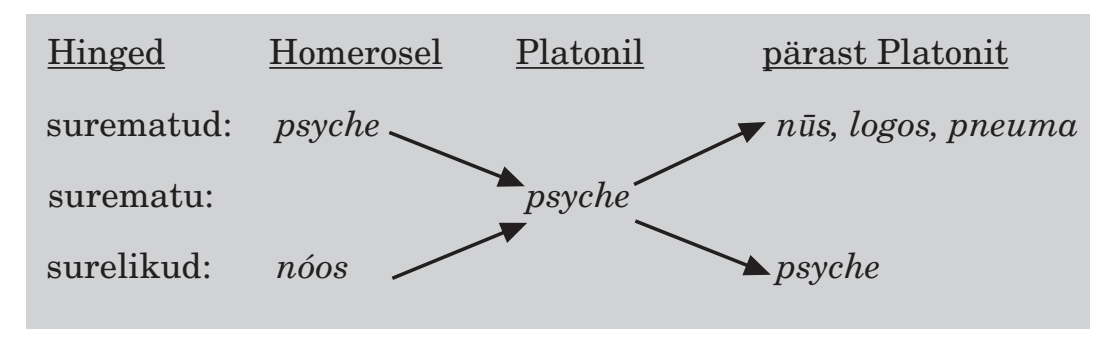

Platoni-järgsest hingemõistest psyche on tuletatud ka näiteks psühholoogia kui hingeteaduse nimetus.

Teisalt tuleb arvestada, et ka germaanlaste maailmapilt on viimastel aastatuhandetel kristliku kultuuri mõjul oluliselt muutunud. Kui saksa keel (alamsaksa ja hiljem ülemsaksa ning baltisaksa murded) on meie keelt ja meelt mõjutanud alates 13. sajandist, siis germaani mõju ulatub ajas väga kaugele. Germaani keeltest, v.a islandi keelest, on praeguseks kadunud nende muistne *ferh- (vrd vanainglise feorh, anglosaksi ja vanaülemsaksa ferah, keskülemsaksa verch, muinaspõhja fjor) tähenduses 'elu, elamisprintsiip loomadel ja inimestel, konkreetne elu substants'. See mõiste oli hingushinge-eelne ning ei tähistanud hinge, mis elab pärast keha surma edasi. Selle hinge asukohaks oli arvatavasti vahelihas, rind või süda. Seega oli *ferh- materiaalne, kehaga seotud hing ja see vastandus hingele, mida tähistab saksa Seele (vrd vanainglise sawul, anglosaksi seola, vanaülemsaksa sêla, keskülemsaksa sêle ja muinaspõhja sál(a)) (LaFarge 1991). Kristlike ettekujutuste mõjul hakati näiteks vanainglise keeles inimestest kõneledes psyche / anima puhul kasutama sawul, loomade puhul kasutati nii sawul kui ka feorh / ferah. Hiljem jäi sawul / seola / sêla tähistama ainult inimhinge, vrd näiteks saksa Seele ja inglise soul.

Vanainglise gast, anglosaksi gêst, vana- ja keskülemsaksa geist (vrd saksa Geist) koos hingesõnadega sawul / sêle tähistasid inimese 


\section{Urmas Sutrop}

surematut osa. Vanainglise lif, anglosaksi lîf, muinaspõhja líf, vanaja keskülemsaksa lîp (vrd saksa Leben ja inglise life) väljendasid inimese olekut siin- või sealpoolses ilmas, s.t ka pärast surma. Mõiste ja vastav sõna lif / lîp tõrjusidki germaani keeltest välja *ferhmõiste ja vastava sõnapere.

Kui sawul / sêle muutus kristluse mõjul anima osaliseks vasteks, siis gast-/geist-sõnadest tehti ladina pneuma/spirituse mõjul nii hingamise kui ka jumala vaimu vaste. Seega anti sellele hingushinge omadusi. Kuid ega germaani keeltes hinge mõisted praegugi üksüheses vastavuses ole. Näiteks inglise soul saksa vasteteks võivad olla nii Seele, Gefühl, Gemüt kui ka Herz. Viimane vaste Herz 'süda' osutab südamele kui hinge võimalikule asupaigale, aga hing võib olla samane ka tundega (Gefühl) või väljendada südant, hinge ja meelt korraga (Gemüt).

Kui alam- ja ülemsaksa keel alates 13. sajandist eesti keelt tugevalt mõjutama hakkasid, tegid saksa pastorid hingushingest hing saksa Seele (psyche / anima) vaste, vaimust aga saksa Geisti (pneuma / spiritus) vaste. Seega sai vaim (tuikamis- ehk tuksumishing) hingushinge hing omadusi. Siit näeme, kuivõrd keerukad on maailmapildi kihistuste seosed keelemälus. Me ei pea mitte vaatama ainult seda, kuidas saksa keel on meie muistse maailmapildi segamini keeranud, vaid ka seda, kuidas kristlus on germaani maailmapilti seganud. Germaanlastelt oleme palju omaks võtnud, kuid kõik see pole olnud germaani, vaid tihti ainult germaanlaste vahendatud kristluse mõju. Nagu juba nägime, vahetasid ka kreeka hingemõisted oma tähendusi.

Siin peame veel arvestama, et kristlik terminoloogia, kus vastanduvad psyche / anima ja pneuma / spiritus (vastavalt saksa Seele ja Geist ning eesti hing ja vaim), on seatud kuidagiviisi vastavusse vanatestamentliku israeliitide hingekontseptsiooniga. Hinge nefeš (elujõud ja eluvõim) asukoht on veri. Koos inimesega sureb tema elujõud. Kuni inimene elab, jääb tema nefeš muutumatuks. Seda tõlgitakse siis psyche / anima / Seele / hing. Kuna savist valmistatud golem on veretu monstrum, siis puudub tal ka hing nefeš. Loomaverd ei tohi aga toiduks tarvitada, sest see sisaldab hinge nefešit.

Sisemine hing, mis seotud mentaalse vallaga, kandis israeliitidel nimetust rûah. Ta võis elu jooksul muutuda, oli väga liikuv ning teda märkiv sõna tähistas ka liikuvat õhku, tuult. Ei olegi selge, kas rûah oli inimese või jumala oma. Seega osutas rûah dü- 
naamilisele suhtele inimese ja jumala vahel. Esialgu oli inimesel ainult üks rûah, hiljem arvati neid olevat rohkem. Seda mõistet tõlgitakse siis pneuma / spiritus / Geist / vaim (vt Hasenfratz 1986: 7681). Isegi nii pealiskaudsel vaatlemisel märkame, et semiidi ja kreeka-ladina hingemõisted on vägagi erinevad.

Kristlikus terminoloogias on saksa Geistil järgmised tähendused: 1) hingeõhk, hingamine, hingus, hõng, ka tuuleõhk, millele Vanas Testamendis vastab heebrea rûah, kreeka pneuma ja ladina spiritus, neist hingushinge tähendustest on arenenud eluprintsiip; 2) kehatud olendid, nagu vaimud ja deemonid, ka kurivaim ehk kurat, ning 3) teadvus, mõtlemisvõime (vrd kreeka logos, nous, ladina animus).

Saksa Seele on kristlikus traditsioonis palju ebamäärasem. Ühelt poolt on see küll vasteks heebrea mõistele nefeš, vrd kreeka psyche (nii Homerose-aegne kui ka Platoni-järgne), ladina anima. Seele on ühelt poolt hingushing, mis on eluprintsiibiks kõigile elavatele, aga sellele vastab ka india âtmā (atman) 'ise', mis võib küll (kuid ei pruugi) olla seotud saksa sõnaga atmen 'hingama'. Samuti on Seele kõikvõimalike hingenähtuste ja nende nimetuste vasteks loodusrahvaste ja muudes mittekristlikes kultuurides. Ka ladina sõnade anima ja spiritus tähendused on suuresti kattuvad. Kreeka päritolu anima 'hingav' < á $\omega$, án $\mu \imath$ 'hingama' on konkreetsem, seevastu ladina spiritus 'hingus, hingeõhk, hõng' jne on oma tähenduselt abstraktsem.

Oskar Loorits kirjutab, et liivi keeles on hinge vasteks jeng, mis tähendab hingamist, hingust (Atem, Hauch), igasuguse elava olevuse hinge (Seele), surnu hinge, haldjat ja deemonit ning lõpuks üldse igasugust üleloomulikku vaimu või olevust. Liivi jeng tähistab siis nii hinge kui ka vaimu, viimase tähistamiseks on läti keelest laenatud gara (vrd läti gars). O. Loorits tunnistab:

[---] liivi keeles kiriku ja kes teab milliste muude asjaolude mõjul moodsaks ja üldtarvitetavaks saand läti laensõna gara vastab täielikult eesti vaim-sõna tähenduslikkele funktsioonele ja tarvitamisrohkusele. Aga mis see "vaim"-sõna siis Eestiski lõppude lõpuks muud on, kui tõlkelaen saksa Geist-sõnast (üliloomuliku olevuse tähenduses) või vähemalt saksa keele mõjul ja jällegi just saksa pastorite ehk "vaimulikkude" kaudu! - eesti keeles nii laiali levinenud (Loorits 1998 I: 16). 


\section{Urmas Sutrop}

Mentaalse maailmapildi vanimasse kihistusse, mida keel mäletab, kuulub sõna ise. Ise oli hing, mis arenes välja kahest komponendist: inimest pidevalt saatnud varjust ja unenägudest. Selline ise saatis inimest alati. Alles hilisemal abstraktsiooniastmel oli võimalik nn hingushinge - hinge - kujunemine. Põhjus on siin väga lihtne. Hing lahkub kehast kahel viisil: lõplikult või ajutiselt. See, kes on meie juurest ära läinud, s.t surnu, ei hinga enam. Lovesse langenud šamaan aga hingab, kuigi ka tema hing usutakse olevat kehast lahkunud. Meie muistsetel esivanematel tuli ületada keeruline vastuolu (kuigi hing on kehast lahkunud, inimene siiski hingab), enne kui sai kujuneda hingushing - hing.

Hingushinges peituvat elujõudu rakendatakse puhumisega. Kui emad puhuvad oma laste valutavatele kohtadele, näiteks äralöödud varba või ukse vahele jäänud sõrme peale, siis ei mäletagi nad, et nad puhuvad lapse haigele kohale peale oma hingejõudu.

Peale ise ning sõnade hing, vaim ja meel kuuluvad mentaalsesse maailmapilti veel jumi, vari, leil jt. Ivar Paulson ütleb näiteks, et irdhinge nimetustena tulevad arvesse sellised sõnad nagu vari, $k u j u$, nägu, aga ka hing ehk vaim. Inimesele antakse eluteele kaasa eriline varustus: tema vägi, õnn, osa, saatus, nimi jt (Paulson 1997: 131-133).

See, et nimi on ise hing või vähemasti hingega seotud, näitab tänapäevanegi (nt ajakirjanduslik) arusaam. Ajakirjanik Rein Sikk kirjutab Eesti Päevalehes artiklis "Ivanidest saavad Juhanid ja Lebedevidest Luiged":

Eesti rahvalaulud ja vanasõnad peavad nime sama oluliseks kui hinge. Kes annab nime ära, kaotab hinge, väidab folkloor. Tänapäeval pü̈takse uue nimega saada uut hinge, kaubamärki, identiteeti (Sikk 1999).

Siin tasuks meenutada vanasõna: Nimi ei riku meest.

Mati Hint on osutanud:

Eestis kõneldavas eesti keeles pole enam eriti palju soomeugrilist südant, sagedasem on vene hing. Eesti keeles on väga palju südamega ja südamevaluga seotud väljendeid, nüüd aga räägivad isegi stiilimeistrid ainult sellest, kuidas üks või teine asi läheb hinge, nii et hing valutab ja asi jääbki hinge peale. Süda jääb arhaismina alles Koidula luuletustesse ja arhaismiks muutuvasse südametunnistusse (Hint 1996: 802). 
Samas ei tohi unustada, et osa südamega seotud väljendeid võivad olla hoopis saksamõjulised, näiteks ei jätku südant või süda kukkus saapasä̈̈rde, vrd saksa der Bruder brachte das nicht übers Herz der Hammel zu schlachten ja vene у брата не хватило духу зарезать барана või saksa das Herz fiel mir (ihm) in die Hosen ja vene душа в пяатки ушла (Graf 1954: 24-25).

Edasisel analüüsil tuleb rohkem arvestada sellega, et meel, hing ja vaim on tugeva saksa ning ka vene mõju all. Et neist muistset rahvatarkust üles leida ja toonast maailmapilti rekonstrueerida, peame need sõnad kõigepealt saksa ja vene mõjust vabastama. Loomulikult moodustab ka hiline saksastatud rahvatarkus osa meie hiljutisest maailmapildist. Keel mäletab ka seda.

\section{Märkus}

Peale käsikirja loovutamist Mare Kõivale, kellele kuulub minu südamlik tänu, on ilmunud Asta Õimu huvitav artikkel Hing keeles ja meeles (2002). Selles analüüsitakse sõna hing semantilist välja ning fikseeritakse mõned kokkupuutekohad sõnade süda, rind ja põu tähendustega. Artiklis jõutakse järeldusele, et hinge kõige füüsilisem ja algsem tähendus on hingamine, kõige abstraktsem - mentaalne mina.

Äsja ilmus minu toimetatuna Uku Masingu keelefilosoofiline raamat Keelest ja meelest (2004). Selles on põhjalikult juttu ka meelest, hingest ja vaimust.

\section{Kirjandus}

Graf, Adolf Eduard 1954. Idiomatische Redewendungen der russischen und deutschen Sprache. Berlin: Deutscher Verlag der Wissenschaften.

Hasenfratz, Hans-Peter 1986. Die Seele: Einführung in ein religiöses Grundphänomen (mit ausgewählten Texten). Zürich:Theologischer Verlag.

Hint, Mati 1996. Eesti keel okupatsiooni järel. Keel ja Kirjandus 12, lk 802-808.

Kulmar, Tarmo 1997. Conceptions of soul in Old-Estonian religion. Folklore 4, lk 27-33.

Kulmar, Tarmo 1998. Eesti muinasusundi hingefenomenoloogia probleeme. Sator 1:Artikleid usundi-ja kombeloost. Tartu: Eesti Keele Instituudi rahvausundi töörühm, lk 38-49. 


\section{Urmas Sutrop}

LaFarge, Beatrice 1991. "Leben" und "Seele" in den altgermanischen Sprachen:Studien zum Einfluß christlich-lateinischer Vorstellungen auf die Volkssprachen. Skandinavistische Arbeiten 11. Heidelberg: Carl Winter Universitätsverlag.

Loorits, Oskar 1990. Eesti rahvausundi maailmavaade. Tallinn: Perioodika.

Loorits, Oskar 1998. Liivi rahva usund I-III. Faksiimiletrükk. Tartu: Eesti Keele Instituudi rahvausundi töörühm.

Masing, Uku 1995. Eesti usund. Tartu: Ilmamaa.

Masing, Uku 1998. Mõtteteaduse sõnavara olukorrast. Meil on lootust. Eesti mõttelugu 19. Tartu: Ilmamaa, lk 355-361.

Masing, Uku 2004. Keelest ja meelest. Taevapõdra rahvaste meelest ehk juttu boreaalsest hoiakust. Tartu: Ilmamaa.

Paulson, Ivar 1997. Vana eesti rahvausk: Usundiloolisi esseid. Tartu: Ilmamaa.

Peebo, Kadri \& Peegel, Juhan (koost) 1989. Igal puul oma juur: Murdetekste Jakob Hurda kogust. Tallinn: Eesti Raamat.

Sikk, Rein 1999. Ivanidest saavad Juhanid ja Lebedevidest Luiged. Eesti Päevaleht, 27. oktoober (http://www.epl.ee/artikkel_58172.html - 7. september 2003).

Sutrop, Urmas 1999. Meie esivanemate rahvatarkus ja maailmapilt: mida keel mäletab? Mäetagused 11, lk 113-119.

Vahtre, Lauri 1985. Algul oli jõud. Looming 12, lk 1666-1672.

Vestring, Salomo Heinrich 1998. Eesti-saksa sõnaraamat = Lexicon Esthonico Germanicum. Tartu: Eesti Kirjandusmuuseum (http://www.folklore.ee/ kriku/VESTRING/index.htm - 7. september 2003).

Widengren, Geo (1969). Religionsphänomenologie. Berlin: Walter de Gruyter \& Co.

Õim, Asta 2002. Hing keeles ja meeles. Emakeele Seltsi aastaraamat 47, lk 126-138.

Õim, Haldur 1997. Eesti keele mentaalse maailmapildi allikaid ja piirjooni. Mati Erelt \& Meeli Sedrik \& Ellen Uuspõld (toim). Pühendusteos Huno Rätsepale 28.12.1997. Tartu Ülikooli eesti keele õppetooli toimetised $=$ Publications of the Department of Estonian of the University of Tartu 7. Tartu; Tartu Ülikool, lk 255-268. 